\title{
Supplementary material S1
}

\section{Content and structure of online questionnaire}

Dear WP1 partners,

As agreed at the KO meeting, all participants in WP1 are expected to act as national representatives and support the gathering of background information that is required to develop the JERICO-RI science strategy. Through Task 1.1, a questionnaire has now been developed to obtain this background information. The objectives of Task 1.1 are to identify the main environmental problems and threats within European coastal waters, and to gather a comprehensive (meta)database on current monitoring programmes operated in Europe for the purposes of the WFD and MSFD. A key aspect of the task is the identification of any gaps in monitoring.

This questionnaire is now being distributed to you as national representative. You are required to respond to the questionnaire to the best of your knowledge and/or take responsibility for completion of the questionnaire. In some cases, it may be necessary to pass the form on to the relevant institutions or authorities within country. You may also forward the questionnaire to colleagues outside your country and not members of the JERICO-NEXT consortium, if you would find it appropriate. In the latter case, please inform Suzanne Painting and/or Kate Collingridge at CEFAS.

In addition to knowledge at regional and national level, we strongly recommend to use outcomes of other EU projects that focuses on threats in EU waters (ex: EU BON, DEVOTES, KNOWSEAS, etc.), when appropriate.

The questionnaire has been developed in a format which facilitates database analysis of the information returned. It needs to be completed (and submitted) online, using Google forms, and includes two linked forms/questionnaires.

1.The first questionnaire is to identify threats in European Seas, and to assess whether existing monitoring programs are adequate.

2. The second questionnaire is to provide information on current monitoring programmes. This form includes a link to a spreadsheet so that information on monitoring stations can be provided.

Click on the link to begin the questionnaire/s: Environmental Threats and Monitoring. Instructions are provided in the questionnaire, and some tips for completing it are attached to this email.

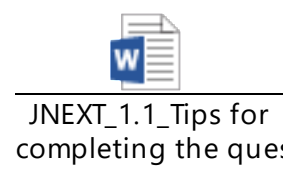

\section{FORM 1 Threats and gaps in monitoring}

\section{SECTION 1}

Q1 Name*

Please provide the name of the person filling in the questionnaire

Q3 Email address*

Please provide the email address of the person filling in the questionnaire 
Please provide the institute or affiliation of the person filling in the questionnaire

Q5 Country (select one)

- Albania

- Belgium

- Bulgaria

- Cyprus

- Denmark

- Estonia

- Finland

- France

- Germany

- Greece

- Ireland

- Italy

- Latvia

- Lithuania

- Malta

- Montenegro

- Netherlands

- Norway

- Poland

- Portugal

- Romania

- Russia

- Slovenia

- Spain

- Sweden

- Turkey

- Ukraine

- United Kingdom

Q6 Region (select one)

(A drop-down list includes regions defined in various ways, e.g. territorial/national/EEZ waters, by ICES, by HELCOM, etc. Some regions have linked sub-regions.

\begin{tabular}{|l|l|}
\hline \multicolumn{1}{|c|}{ Region } & Go to section \\
\hline 1 Baltic Sea & $\begin{array}{l}2 \text { (Baltic Sea } \\
\text { Subregions }\end{array}$ \\
\hline 2 Belt Sea & 12 (Threats) \\
\hline 3 The Sound & 12 (Threats) \\
\hline 4 Kattegat & 12 (Threats) \\
\hline 5 Skaggerak & 12 (Threats) \\
\hline I Barents Sea & 12 (Threats) \\
\hline $\begin{array}{l}\text { II Norwegian Sea, } \\
\text { Spitzbergen and Bear } \\
\text { Island }\end{array}$ & $\begin{array}{l}3 \text { (Norwegian Sea } \\
\text { Subregions) }\end{array}$ \\
\hline IV North Sea & $\begin{array}{l}4 \text { (North Sea } \\
\text { Subregions) }\end{array}$ \\
\hline $\begin{array}{l}\text { V Iceland and Faroes } \\
\text { Grounds }\end{array}$ & $\begin{array}{l}5 \text { (Region V } \\
\text { Subregions) }\end{array}$ \\
\hline VI Rockall and West of & $\begin{array}{l}6 \text { (Region VI } \\
\text { Subregions) }\end{array}$ \\
\hline Vcotland & $\begin{array}{l}7 \text { (Region VII } \\
\text { Subregions) }\end{array}$ \\
\hline VIII Bay of Biscay & $\begin{array}{l}8 \text { (Region VIII } \\
\text { Subregions) }\end{array}$ \\
\hline IX Portuguese Waters & $\begin{array}{l}9 \text { (Region IX } \\
\text { Subregions) }\end{array}$ \\
\hline Mediterranean Sea & $\begin{array}{l}10 \text { (Mediterranean } \\
\text { Sea Subregions }\end{array}$ \\
\hline
\end{tabular}




\begin{tabular}{|l|l|}
\hline Black Sea & $\begin{array}{l}11 \text { (Black Sea } \\
\text { Subregions) }\end{array}$ \\
\hline $\begin{array}{l}\text { Territorial Waters } \\
(12 n m)\end{array}$ & 12 (Threats) \\
\hline EEZ/National Waters & 12 (Threats) \\
\hline North East Atlantic & 12 (Threats) \\
\hline Other & 12 (Threats) \\
\hline
\end{tabular}

Section 2 Baltic Sea Subregions (select multiple)

1.1 Gulf of Bothnia

1.2 Gulf of Finland

1.3 Gulf of Riga

1.4 Baltic Proper

2.1 Bay of Mecklenburg

2.2 Kiel Bay

2.3 Little Belt

2.4 Great Belt

Other

Go to section 12 (Threats)

Section 3 Norwegian Sea Subregions (select multiple)

Ila Norwegian Sea

Ilb Spitzbergen and Bear Island

Other

Go to section 12 (Threats)

Section 4 North Sea Subregions (select multiple)

IVa Northern North Sea

IVb Central North Sea

IVc Southern North Sea

Other

Go to section 12 (Threats)

Section 5 Region V Subregions (select multiple)

Va Iceland Grounds

Vb Faroes Grounds

Other

Go to section 12 (Threats)

Section 6 Region VI Subregions (select multiple)

Vla NW Coast of Scotland and N Ireland

VIb Rockall

Other

Go to section 12 (Threats)

Section 7 Region VII Celtic Seas Subregions (select multiple)

VIla Irish Sea

VIlb West of Ireland

VIIc Porcupine Bank

VIId Eastern English Channel

VIle Western English Channel

VIIf Bristol Channel

VIlg Celtic Sea North

VIlh Celtic Sea South

VIlj SW of Ireland - East

VIlk SW of Ireland - West

Other

Go to section 12 (Threats)

Section 8 Region VIII Subregions (select multiple)

VIIla Bay of Biscay - North

VIIlb Bay of Biscay - Central 
VIIlc Bay of Biscay - South

VIIld Bay of Biscay- Offshore

VIIle West Bay of Biscay

IXa Portuguese Waters - East

IXb Portuguese Waters - West

Other

Go to section 12 (Threats)

Section 9 Region IX Subregions (select multiple)

IXa Portuguese Waters - East

$\mathrm{IXb}$ Portuguese Waters - West

Other

Go to section 12 (Threats)

Section 10 Mediterranean Sea Subregions (select multiple)

1 Northern Alboran Sea

2 Alboran Island

3 Southern Alboran Sea

4 Algeria

5 Balearic Islands

6 Northern Spain

7 Gulf of Lyons

8 Corsica Island

9 Ligurian and North Tyrrhenian Sea

10 South Tyrrhenian Sea

11 Sardinia

12 Northern Tunisia

13 Gulf of Hammamet

14 Gulf of Gabes

15 Malta Island

16 South of Sicily

17 Northern Adriatic Sea

18 Southern Adriatic Sea

19 Western Ionian Sea

20 Eastern Ionian Sea

21 Southern Ionian Sea

22 Aegean Sea

23 Crete Island

24 North Levant

25 Cyprus Island

26 South Levant

27 Levant

28 Marmara Sea

Other

Go to section 12 (Threats)

Section 11 Black Sea Subregions (select multiple)

29 Black Sea

30 Asov Sea

Other

Go to section 12 (Threats)

\section{Section 12 Threats}

Threats to the marine environment are considered here in terms of 'pressures' and 'impacts'. Pressures are the human activities which have impacts on ecosystems or parts thereof. Impacts may become threats, but should be able to be linked back to the original pressure. Checklists of pressures and impacts are given below. Multiple options can be selected. Other pressures and impacts can also be added, and details can be given to provide explanation/s.

Q1 Pressures (select multiple)

What are the main pressures from human activities that are affecting the environment in this area? Details can be given below. 
- Construction/Obstruction

- Shipping

- Mining

- Dumping

- Extraction (e.g. of aggregates such as gravels or sand)

- Abstraction (removal of water, e.g. for aquaculture)

- Marine litter

- Aquaculture

- Contaminants

- Inorganic nutrient enrichment

- Organic enrichment

- Atmospheric inputs

- Fishing

- Dredging of biota (e.g. scallops, clams)

- Regime change (thermal)

- Regime change (salinity)

- Other

Q2 (free text)

Please provide any necessary details on the above pressures

Q3 Impacts (select multiple)

What are the impacts resulting from the pressures identified above?

- Physical damage (abrasion, material extraction)

- Changes in hydrology

- Underwater noise disturbance

- Changes in sediment/substrate composition

- Habitat loss or destruction

- Changes in suspended sediments/turbidity

- Changes in light availability

- Contamination (with harmful substances etc)

- Biofouling

- Invasive species

- Harmful micro-organisms (such as harmful algal blooms)

- Increased or decreased primary production (e.g. by phytoplankton or macroalgae)

- Undesirable disturbances (e.g. oxygen depletion due to nutrient enrichment (eutrophication))

- Population change/depletion of standing stock

- Changes in species range

- Changes in community composition

- Mortality of marine life

- Other

Q4 (free text)

Please provide any necessary details on the above impacts

Q5 Policy Purposes (select multiple)

What are the main policy or other drivers behind the monitoring programme/s? These may be international conventions, EU Directives, national policies, or other requirements.

- Marine Strategy Framework Directive (MSFD)

- ospar

- Water Framework Directive (WFD)

- Urban Waste Water Treatment Directive (UWWTD)

- Local

- Other:

Q6 MSFD Descriptors (select multiple)

The MSFD includes 11 qualitative descriptors. Please link the threats identified to these descriptors, or any others which may be relevant in the area.

- 1 Biodiversity 
- 2 Non-native species

- 3 Fish

- 4 Food Webs

- 5 Eutrophication

- 6 Sea Floor Integrity

- 7 Hydrographic conditions

- 8 Contaminants in water

- 9 Contaminants in food

- 10 Marine Litter

- 11 Energy

Q7 Please name any relevant monitoring programmes(s) * (free text)

If there are multiple programs, please separate by commas. A form is provided at the end of the questionnaire to provide details of the programme/s. If there is no relevant monitoring, type 'none'.

Q7 Are existing monitoring programmes sufficient to assess the effects of the environmental threats in the considered area? (select one)

- Yes

- No

- Partly

Q7a If no (or partly), please explain how they are deficient (free text)

For example, no monitoring in the area considered, inadequate monitoring of parameters, insufficient spatial or temporal resolution of the monitoring

Q7B If no (or partly), please suggest what would be appropriate in terms of monitoring to assess the impact of the considered threats (free text)

Please go to the monitoring form to enter details of the monitoring programmes (one form submission per monitoring programme), using the link below.

http://goo.gl/forms/ZZyCrZEu2w1ouFw22

\section{FORM 2 Monitoring programmes}

Please complete one form entry per monitoring programme

Section 1 Country (select one
$\bullet$ Albania
$\bullet$ Belgium
$:$ Bulgaria
$:$ Cyprus
$:$ Estonia
$:$ Finland
$:$ France
$:$ Germany
$:$ Greece
$:$ Ireland
$:$ Laty
$:$ Lithua
$:$ Malta
$:$ Montenegro
$:$ Netherlands
$:$ Norway
- Poland


- Portugal

- Romania

- Russia

- Slovenia

- Spain

- Sweden

- Turkey

- Ukraine

- United Kingdom

\section{Section 2 Monitoring details}

\section{Q1 Monitoring program name}

Q2 Is this monitoring program a statutory/official program or an 'unofficial' project/program?

E.g. An 'official' monitoring program contributes towards obligations under various legal instruments and is likely to be funded by the government/state; an 'unofficial' program includes monitoring for other reasons and is likely to reply on other sources of funding (e.g. EU, commercial).

Q3 Variables measured* (select multiple)

- Temperature

- Salinity

- Nutrients

- Dissolved Gases

- Chlorophyll

- $\mathrm{pH}$

- Plankton

- Benthos

- Macroalgae

- Hydrography

- Contaminants

- Litter

- Fish

Q4 Platform types (select multiple)

- Shore based

- Research Vessel

- Voluntary Observing Ship (VOS)

- Small Boat

- Ferrybox (fixed transects)

- Ferrybox (cruise of opportunity)

- Fixed platform

- Remote Sensing

- Autonomous vehicle (ROV, AUV, Glider etc)

- Other

\section{Q5 Number of stations}

Total approximate number of stations monitored

Q6 Is monitoring regular or ad hoc?

- Regular

- Ad hoc

- Other

Q7 If monitoring is regular, what is the monitoring frequency?

- Continuous

- Hourly

- Daily

- Weekly

- Monthly 
- Annually

\section{Q8 Start date}

\section{Q9 End date}

If ongoing please enter today's date

Q10 If the monitoring program has ended, please provide a reason.

E.g. funding not renewed, threats no longer present so monitoring not required.

\section{Monitoring stations}

To provide details of the location etc of monitoring stations please follow the link:

https://docs.google.com/spreadsheets/d/126UXCWvEIVwiq06N 1lm6yAgD4YDU2IAPy-

CmshEjbo/edit?usp=sharing

Comments (free text)

\section{Section 3 Data Access}

Q1 Data access restrictions

Are there restrictions on data access?

- Yes

- No

Q2 Data access details (short answer text)

Details of data access restrictions

Q3 Responsible organisation (short answer text)

Q4 Responsible person (short answer text)

Q5 Postal address (short answer text)

Q6 Email address (short answer text)

Q7 Phone number (short answer text)

Q8 Data source institute(s) (short answer text)

Q9 Database (select multiple)

Database to which the monitoring data are submitted

- BODC MERMAN

- ICES DOME

- EMODNET

- EA

- Local

- Other

Q10 Data flows (select one)

Are data flows to central data holders (e.g. ICES) established and up to date?

- Yes

- No

- Other

\section{Q11 Web links}

Link to online location of data

Q12 Comments (free text)

Q9 Research Database (select multiple)

Complementary oceanographic or research databases 
- BODC NODB

- ICES OCEAN

- Local

- Other

Q10 Research Data flows (select one)

Are data flows to central data holders (e.g. ICES) established and up to date?

- Yes

- No

- Other

Q11 Web links

Link to online location of data

Q12 Research Comments (free text) 